Research, Society and Development, v. 10, n. 12, e530101220718, 2021

(CC BY 4.0) | ISSN 2525-3409 | DOI: http://dx.doi.org/10.33448/rsd-v10i12.20718

\title{
Dança, psicomotricidade e educação infantil: revisão de literatura e considerações para uma educação física escolar significativa
}

\author{
Dance, psychomotricity and early childhood education: literature review and considerations for a \\ significant school physical education \\ Danza, psicomotricidad y educación de la primera infancia: revisión de la literatura y \\ consideraciones para una educación física escolar significativa
}

Recebido: 16/09/2021 | Revisado: 24/09/2021 | Aceito: 28/09/2021 | Publicado: 29/09/2021

\author{
Raphael Almeida Silva Soares \\ ORCID: https://orcid.org/0000-0001-5818-3004 \\ Universidade Salgado de Oliveira, Brasil \\ E-mail: raphasilvasoaresss@gmail.com \\ Catia Malachias Silva \\ ORCID: https://orcid.org/0000-0003-3420-061X \\ Centro Universitário São José, Brasil \\ E-mail: catiamalachiass@gmail.com \\ Deivid Pereira Queiroz \\ ORCID: https://orcid.org/0000-0002-6938-7819 \\ Universidade Salgado de Oliveira, Brasil \\ E-mail: deividpq@hotmail.com \\ Susana Reis Santos \\ ORCID: https://orcid.org/0000-0002-3148-1789 \\ Centro Universitário São José, Brasil \\ E-mail: edufisicaautodor@gmail.com \\ Thaíza Fonseca Lima Miranda \\ ORCID: https://orcid.org/0000-0003-0760-4678 \\ Universidade Salgado de Oliveira, Brasil \\ E-mail:thaizafl@gmail.com
}

\begin{abstract}
Resumo
Desde os tempos mais remotos a dança representa expressão e linguagem corporal. De acordo com os Parâmetros Curriculares Nacionais, a educação física é a área de conhecimento responsável por incluir as danças enquanto cultura corporal de movimento. O presente estudo tem como objetivo revisar a literatura acerca da temática e discutir a dança, o desenvolvimento psicomotor e as estratégias voltadas para a Educação Infantil mediante ao planejamento e execução dessas atividades nas aulas de Educação Física Escolar. A presente pesquisa caracteriza-se enquanto uma revisão sistemática da literatura. As buscas foram realizadas nas seguintes bases de dados: Google Acadêmico, MOSAICO, LILACS, SCiELO e o Catálogo de Teses e Dissertações da CAPES. As estratégias de busca foram montadas com base nos descritores: dança, psicomotricidade, educação física, educação escolar, educação física escolar, educação infantil, e ensino infantil. Um total de 2.425 documentos foram encontrados e após leitura completa e seleção dos textos, 8 estudos foram retidos para análise. Os achados sugerem que a dança enquanto estratégia psicomotora, possibilita a expressão de sentimentos e estruturação das funções psicomotoras que as crianças necessitam para sua formação global. As aulas devem levar em consideração a cultura regional e priorizar a qualidade da intervenção ao invés da quantidade de atividades oferecidas. A dança na escola ainda é uma temática pouco explorada ou negligenciada. Tal fato reverbera no baixo quantitativo de estudos retidos para análise. Por outro lado, apresenta um vasto campo de possibilidades para produção científica.
\end{abstract}

Palavras-chave: Aprendizagem Motora; Desenvolvimento Cognitivo; Educação Significativa; Crianças.

\begin{abstract}
Since ancient times, dance represents expression and body language. According to the National Curriculum Parameters, physical education is the area of knowledge responsible for including dances as a movement body culture. This study aims to review the literature on the subject and discuss dance, psychomotor development and strategies aimed at Early Childhood Education through the planning and execution of these activities in Physical Education classes. The present research is characterized as a systematic review of the literature. Searches were performed in the following databases:
\end{abstract}


Research, Society and Development, v. 10, n. 12, e530101220718, 2021

(CC BY 4.0) | ISSN 2525-3409 | DOI: http://dx.doi.org/10.33448/rsd-v10i12.20718

Academic Google, MOSAICO, LILACS, SCiELO and the CAPES Theses and Dissertations Catalog. The search strategies were set up based on the descriptors: dance, psychomotricity, physical education, school education, school physical education, early childhood education, and early childhood education. A total of 2,425 documents were found and after complete reading and selection of texts, 8 studies were retained for analysis. The findings suggest that dance, as a psychomotor strategy, enables the expression of feelings and the structuring of the psychomotor functions that children need for their global formation. Classes must take into account the regional culture and prioritize the quality of the intervention over the quantity of activities offered. Dance at school is still an underexplored or neglected theme. This fact is reflected in the low number of studies retained for analysis. On the other hand, it presents a vast field of possibilities for scientific production.

Keywords: Motor Learning; Cognitive Development; Meaningful Education; Kids.

\section{Resumen}

Desde la antigüedad, la danza representa la expresión y el lenguaje corporal. Según los Parámetros Curriculares Nacionales, la educación física es el área de conocimiento encargada de incluir la danza como movimiento corporal de la cultura. Este estudio tiene como objetivo revisar la literatura sobre el tema y discutir la danza, el desarrollo psicomotor y las estrategias dirigidas a la Educación Infantil a través de la planificación y ejecución de estas actividades en las clases de Educación Física. La presente investigación se caracteriza por ser una revisión sistemática de la literatura. Las búsquedas se realizaron en las siguientes bases de datos: Google Académico, MOSAICO, LILACS, SCiELO y el Catálogo de Tesis y Disertaciones CAPES. Las estrategias de búsqueda se configuraron a partir de los descriptores: danza, psicomotricidad, educación física, educación escolar, educación física escolar, educación infantil y educación infantil. Se encontraron un total de 2.425 documentos y después de la lectura completa y la selección de textos, se conservaron 8 estudios para su análisis. Los hallazgos sugieren que la danza, como estrategia psicomotora, posibilita la expresión de sentimientos y la estructuración de las funciones psicomotoras que los niños necesitan para su formación global. Las clases deben tener en cuenta la cultura regional y priorizar la calidad de la intervención sobre la cantidad de actividades ofrecidas. La danza en la escuela sigue siendo un tema poco explorado o olvidado. Este hecho se refleja en el escaso número de estudios que se conservan para el análisis. Por otro lado, presenta un vasto campo de posibilidades para la producción científica.

Palabras clave: Aprendizaje Motor; Desarrollo Cognitivo; Educación Significativa; Niños.

\section{Introdução}

Ao falar da dança, deve-se analisar a sua trajetória ao longo dos anos, pois ao se pesquisar sobre a sociedade e a civilização que nela habita, dos dias atuais aos mais remotos, percebe-se a dança como atividades de expressões culturais e linguagem corporal (Marques, 1998; Diniz \& Santos, 2009). Nesse sentido, autores contemporâneos entendem sua importância e relevância para um processo de educação significativo (Nascimento \& Silva Lopes, 2021), enfatizando as danças regionais e folclóricas brasileiras como parte desse processo (Magalhães, 2021).

Ao refletir sobre a história do homem, percebe-se que os primeiros indícios da dança na pré-história foram por registros arqueológicos que ao serem interpretados puderam mostrar que a dança nasceu da religião, onde o homem possuía uma necessidade de expressar através da mesma, todos os acontecimentos sociais como nascimentos, casamentos, ótimas caças, colheitas e festas (Franco \& Ferreira, 2016). A dança na Pré-História ajudou a desenvolver o senso motor, cognitivo e socioafetivo do homem, através da sua ação comunicativa, utilizada como forma de se manifestar exibindo qualidades físicas e expressando sentimentos. É fundamental a compreensão da dança como uma linguagem que caminhe lado a lado com a produção de conhecimento e a vida em sociedade, despertando em seus praticantes uma consciência crítica e criativa (Gariba \& Franzoni, 2007).

De acordo com os Parâmetros Curriculares Nacionais (PCNs) (Brasil, 1997; Brasil, 2001), a educação física é a área de conhecimento responsável por mediar as manifestações e expressões corporais que incluem as danças enquanto bloco de conteúdo da cultura corporal de movimento. Além disso, os PCNs sugerem os temas transversais Pluralidade Cultural e Educação Das Relações Étnico-Raciais que são carregados de manifestações populares que incluem as danças no universo escolar. Embora o documento atual normativo para a educação brasileira seja a Base Nacional Comum Curricular (BNCC), (Silva Mello, et al., 2016) optamos pela utilização dos PCNs em detrimento das tensões geradas pela BNCC enquanto um documento que põe em 
xeque os processos democráticos em sua implementação (Silva Holanda, et al., 2021) provocando impactos significativos na formação de professores e alunos (Gomes \& Silva Souza, 2021; Barreto, et al., 2021).

Por meio das danças também se faz possível o desenvolvimento das artes visuais, das artes cênicas e da musicalidade (Neves, 2014). Dessa maneira a dança enquanto conteúdo escolar, promove diferentes experiências com o corpo para além do quarteto de esportes: futebol, basquete, voleibol e handebol (Marques \& Selow, 2017).

$\mathrm{Na}$ educação infantil, utilizar a dança como um instrumento pedagógico é de suma importância, pois desempenha um papel fundamental para o desenvolvimento das funções psicomotoras por meio de atividades que carregam situações desafiadoras, permitindo que as crianças encontrem respostas por si mesmas, contribuindo para sua autonomia. A psicomotricidade pode ser considerada uma ferramenta pedagógica utilizada por professores com o objetivo de colaborar no desenvolvimento da criança. Fonseca (2008) explica que a psicomotricidade é uma ciência baseada nas ideias desenvolvidas por Wallon, Piaget e Ajuriaguerra, pensadores dos processos de desenvolvimento cognitivo e psicomotor que compreendem o desenvolvimento pleno de um ser biopsicossocial.

Esse desenvolvimento é gradativo ao longo do crescimento e das capacidades de adaptação às necessidades básicas (Aquino, et al., 2012). Com base nas definições supracitadas, a dança enquanto manifestação da cultura corporal de movimento, onde, os domínios afetivos, cognitivos e psicomotores são desenvolvidos, pode ser inserida nas aulas de Educação Física Escolar como proposta de educação psicomotricista. Tendo em vista os benefícios da dança nos componentes motor, cognitivo e afetivo social e das funções psicomotoras básicas a seguinte questão de pesquisa foi proposta: Quais são as estratégias utilizadas e quais são os possíveis retornos da dança na Educação Infantil nas aulas de Educação Física Escolar? Por meio dessa pergunta de partida, o presente estudo tem como objetivo revisar a literatura acerca da temática e discutir a dança, o desenvolvimento psicomotor e as estratégias voltadas para a Educação Infantil mediante ao planejamento e execução dessas atividades nas aulas de Educação Física Escolar.

\section{Fundamentação teórica}

\subsection{Fundamentos e conceitos da psicomotricidade}

Pode ser considerada uma ciência, uma terapia, ou uma técnica, a psicomotricidade utiliza atividades lúdicas para atingir seus objetivos, consiste na utilização da fluidez do corpo para buscar a harmonia do corpo e da mente, o desenvolvimento da afetividade do indivíduo e todos os fatores que determinam sua vivência (Fonseca, 2008).

A teoria de Piaget tem como pressupostos o interacionismo e o construtivismo enquanto fatores que interferem diretamente no desenvolvimento cognitivo. O desenvolvimento psicomotor e a aprendizagem, segundo Fonseca (2008), ao citar as obras de Piaget, segue em uma sequência espiralada que compreende: cognição, inteligência, operações, coordenações e ações por meio de jogos e imitações. Para o autor, o processo de evolução cognitivo encontra-se diretamente relacionado com as capacidades motoras. Aos primeiros anos de vida, ou seja, na primeira infância, que, compreende de 0 a 2 anos de vida, "a criança "faz", mas ainda não compreender o que "faz”. Só mais tarde, por meio de esquemas operacionais, ou seja, por meio dos primeiros passos da ação consciencializada, ela poderá compreender e a saber o que faz pelo que fez” (Fonseca, 2008 p. 85).

Segundo Sousa (2004), o processo de desenvolvimento cognitivo sob o olhar de Piaget está dividido em:

a) Sensório motor ( 0 a 2 anos) - Nesse estágio a criança alcança o nível de elaboração de noções do espaço e tempo;

b) Pré-Operacional (2 aos 6 anos) - Surgimento da linguagem oral, permitindo a simbolização e representação do pensamento. 
c) Operacional concreto (6 aos 11 anos) - Desenvolvimento do pensamento lógico e adaptação ao convívio social.

d) Operacional Formal (acima de 12 anos) - Aprimoramento do potencial cognitivo, permitindo o raciocínio real e imaginário.

A psicomotricidade é uma ferramenta utilizada na Educação Física de bastante importância, pois busca o desenvolvimento na perspectiva integral dos educandos, em seus aspectos motores, cognitivos e afetivos. Além do que, atividades de psicomotricidade auxiliam no desenvolvimento do raciocínio, da imaginação, da criatividade, da socialização e da afetividade (Aquino, et al., 2012). Segundo Sousa (2004), o desenvolvimento psicomotor abrange um desenvolvimento integral de todo o corpo, portanto é comum encontrar esse desenvolvimento organizado em alguns fatores, que são eles: tonicidade, equilíbrio, noção corporal, lateralidade, orientação espaço-temporal, coordenação motora global e coordenação motora fina (ver Figura 1).

Figura 1. Quadro de definição das funções psicomotoras

\section{FUNÇÃo}

Tonicidade

Noção corporal

Lateralidade

Orientação EspaçoTemporal

É caracterizada como uma organização da lateralidade e da noção corporal. Esse fator é importante para a adaptação do indivíduo ao meio em que vive, permitindo o movimento corporal no espaço e sua relação com os objetos a sua volta.

É o alicerce fundamental da psicomotricidade, pois traduz o tônus muscular com a função de garantir a postura, as atitudes e as emoções, de onde surgem todas as atividades motoras humanas. É o tônus muscular que permite todo o movimento corporal.

Pode ser caracterizada como a estruturação do esquema corporal que tem como função a conscientização do próprio corpo e das possibilidades de expressão. É a percepção do corpo atuando no espaço, se locomovendo em um ritmo próprio.

É a percepção dos lados do corpo, tornando-se um fundamental elemento de relação e orientação corporal com o mundo exterior, capacitando o indivíduo a utilizar um lado do corpo com maior facilidade e dominância.

É a capacidade que reúne um conjunto de aptidões estáticas e dinâmicas, que são representadas pela capacidade de orientação e manutenção do corpo em relação ao espaço e à ação da gravidade, englobando o controle da postura e a locomoção. Esse fator está intimamente relacionado com a tonicidade.
Coordenação motora global

Coordenação motora fina

Está relacionada com a realização e automação dos movimentos globais complexos, que são desenvolvidos num determinado tempo e exigem a atividade de diversos grupamentos musculares em conjunto.

Tem como função a verificação e programação das atividades manipulativas mais finas e complexas, representando o mais fino do desenvolvimento motor.

Fonte: adaptado de Souza (2004).

\subsection{Fundamentos e conceitos da dança escolar}

A dança pode ser considerada uma das mais antigas formas de manifestação de expressão corporal, fazendo parte da história desde os tempos primordiais (Darido \& Rangel, 2005). Pode-se dizer que o homem e a dança caminham e evoluem juntos, pois acontecimentos geravam movimentos, emoções e formas de expressão manifestadas exclusivamente pelo homem. 
O homem primitivo possuía incontáveis motivos para dançar: caça, colheita, alegria, tristeza, casamentos e, à medida que esses conteúdos se misturavam, eram criadas formas de expressões e interpretações através da dança. Dessa maneira, entende-se que as danças são diferentes e existem vários tipos. Darido \& Rangel (2005) as classificam nos seguintes tipos:

a) Étnicas: manifestações expressivas de diferentes povos, com atributos divinos e religiosos [...], por exemplo, a valsa, em Viena, a tarantela, na Itália.

b) Folclóricas: abordam os costumes e tradições dos povos ou determinadas regiões distintas da mesma nação [...], o maxixe, o chote, a quadrilha.

c) Danças de salão ou sociais: realizadas nos salões da nobreza real [...], nos dias de hoje podemos citar as danças dos bailes e das festas como o pagode, o funk e o axé.

d) Dança teatral ou artística: [...] é a dança para espetáculos [...], por exemplo, ballet clássico, sapateado, jazz.

A dança se modificou ao longo dos anos, seja no ritmo ou estilo, porém alguns aspectos foram preservados até hoje como: a técnica; a incansável busca pela performance através de treinos intensos; e a exploração da expressividade do movimento. Porém, ao mesmo tempo que esses fatores existem, abriu-se uma grande possibilidade de exploração do movimento, tempo e espaço que traz ferramentas necessárias para os profissionais que pretendem levar a dança para as escolas (Marques \& Selow, 2017).

A dança ao ser aplicada no âmbito escolar, permite que as crianças desenvolvam principalmente a tonicidade, a lateralidade, o equilíbrio e a noção corporal através da ludicidade e expressividade. De todas as artes, a dança é a única que pode ser traduzida apenas pelo corpo, e ao ser desenvolvida como conteúdo escolar, deverá propiciar situações às crianças que estimulem a ação, a compreensão e a reflexão sobre os resultados de suas ações (Verderi, 2000).

Sendo assim, compreendemos que a dança possui uma função pedagógica no ensino, sendo traduzido na criação de movimentos de expressão e criativos, permitindo que as crianças desenvolvam a relação do domínio corporal, aprimorando a sua movimentação, descobrindo novas formas e espaços, superando limites e adquirindo confiança e autoestima para enfrentar novos desafios no que diz respeito a aspectos motores, afetivos e cognitivos.

Segundo Verderi (2000) é importante que o professor possua conhecimento dos fatores que compõe a dança, para que suas aulas sejam efetivas. Para a autora, a dança é constituída por: a) música, composta por melodia e harmonia, se torna um importante fator estimulante para as funções afetivas e sensoriais; b) ritmo, pode ser estimulado através de palmas, estalo de dedos e assobios. Faz parte de tudo que existe no universo, o estímulo que caracteriza a vida e c) movimento que se caracteriza enquanto a mais verdadeira expressão da existência da vida.

Portanto, é de suma importância reforçar que o profissional de Educação Física tem um papel fundamental no processo de ensino aprendizagem, pois as crianças enxergam nos movimentos do seu corpo uma referência para a execução da expressividade e da comunicação corporal. Sabendo disso, a escola não deveria apenas dar ênfases nas performances técnicas ou apresentações artísticas, devem também contribuir diretamente no desenvolvimento humano em aspectos motores, cognitivos e socioafetivos (Souza, 2018; Maciel, et al., 2016; Carmo \& Cintra, 2016; Falsarella \& Amorim, 2008; Gomes \& Nista-Piccolo, 2007).

\section{Procedimentos Metodológicos}

A presente pesquisa tem caráter descritivo, valendo-se de estratégias de revisão sistemática da literatura (Boente \& Braga, 2004; Thomas, et al., 2012). Define-se revisão sistemática como uma síntese rigorosa de pesquisas relacionadas com um 
Research, Society and Development, v. 10, n. 12, e530101220718, 2021

(CC BY 4.0) | ISSN 2525-3409 | DOI: http://dx.doi.org/10.33448/rsd-v10i12.20718

tema específico, tendo como finalidade identificar tendências e apontar possíveis vieses. Para que isso seja possível, são estabelecidos métodos rigorosos, estratégias de busca, bem como implementação de critérios de inclusão e exclusão para os estudos a serem revisados (Dobbins, et al., 2001). Após reunir os dados encontrados na revisão sistemática, as informações são categorizadas e organizadas de forma didática, tornando-as de fácil compreensão e entendimento. Com isso, provê-se suporte para pesquisadores e outros interessados no tema revisado, munindo-os de informações confiáveis e atualizadas (Kitchenham, et al., 2006).

A presente revisão sistemática respeitou os padrões estabelecidos pelas recomendações PRISMA quando incluídos artigos com intervenções clínicas (Galvão, et al., 2015). Estruturamos uma pesquisa sem limite de data entre junho e setembro de 2021, de modo que as categorias de análise foram organizadas mediante a origem do material disponível. A saber: artigos, trabalhos de conclusão de curso, teses e dissertações que tenham sido publicados na íntegra nos idiomas: inglês, espanhol ou português. As buscas foram realizadas nas seguintes bases de dados: Google Acadêmico, MOSAICO - Saúde Integrativa, LILACS, SCiELO e no Catálogo de Teses e Dissertações da CAPES. Na base da CAPES, utilizamos os filtros adicionais Educação e Ciências da Saúde, dessa forma, a busca por teses e dissertações foi direcionada para as áreas temáticas que estamos revisando (educação/educação física).

As estratégias de busca foram montadas com base nos descritores: dança, psicomotricidade, educação física, educação escolar, educação física escolar, educação infantil, e ensino infantil. Os operadores booleanos, $A N D$ e $O R$ foram administrados de acordo com cada base pesquisada. Os resultados encontrados serão apresentados na próxima sessão da seguinte forma: a) fluxograma da revisão sistemática (ver figura 2); b) características dos documentos encontrados (ver tabela 1); b) detalhamento dos estudos e discussão dos resultados a saber as principais considerações para aplicação da dança enquanto estratégia psicomotora.

\section{Resultados e Discussão}

Após a busca inicial os artigos relevantes foram identificados através de dois estágios de triagem, realizados de forma independente e comparados por quatro pesquisadores. Na primeira etapa, títulos e resumos dos resultados da pesquisa foram verificados quanto à relevância. No estágio dois, os textos completos foram localizados e avaliados para inclusão. Foram incluídos artigos e trabalhos de conclusão de curso (TCC) de graduação e pós-graduação e dissertação de mestrado que apresentassem discussões e possibilidades de intervenção com a dança enquanto estratégia psicomotora nas aulas de educação física escolar, direcionadas para a educação infantil. Excluíram-se estudos que não estavam associados ao problema de pesquisa em questão. As bases pesquisadas retornaram um n=2.391 arquivos, contudo, após leitura na integra, apemas 8 estudos foram incluídos. Na tentativa de incluirmos mais estudos para a presente revisão, realizamos buscas adicionais nas revistas, Movimento (UFRGS), Motriz - Revista de Educação Física da UNESP, Motrivivência (UFSC), Pensar a Prática (UFG) e Resvista de Educação Física da UEM. Essa busca retornou um total de 23 artigos, contudo, não houve alteração no resultado final. A Figura 2 apresenta o fluxo de identificação, seleção e inclusão dos estudos na presente revisão sistematica. 
Research, Society and Development, v. 10, n. 12, e530101220718, 2021

(CC BY 4.0) | ISSN 2525-3409 | DOI: http://dx.doi.org/10.33448/rsd-v10i12.20718

Figura 2. Diagrama de fluxo para inclusão dos estudos na revisão sistemática.

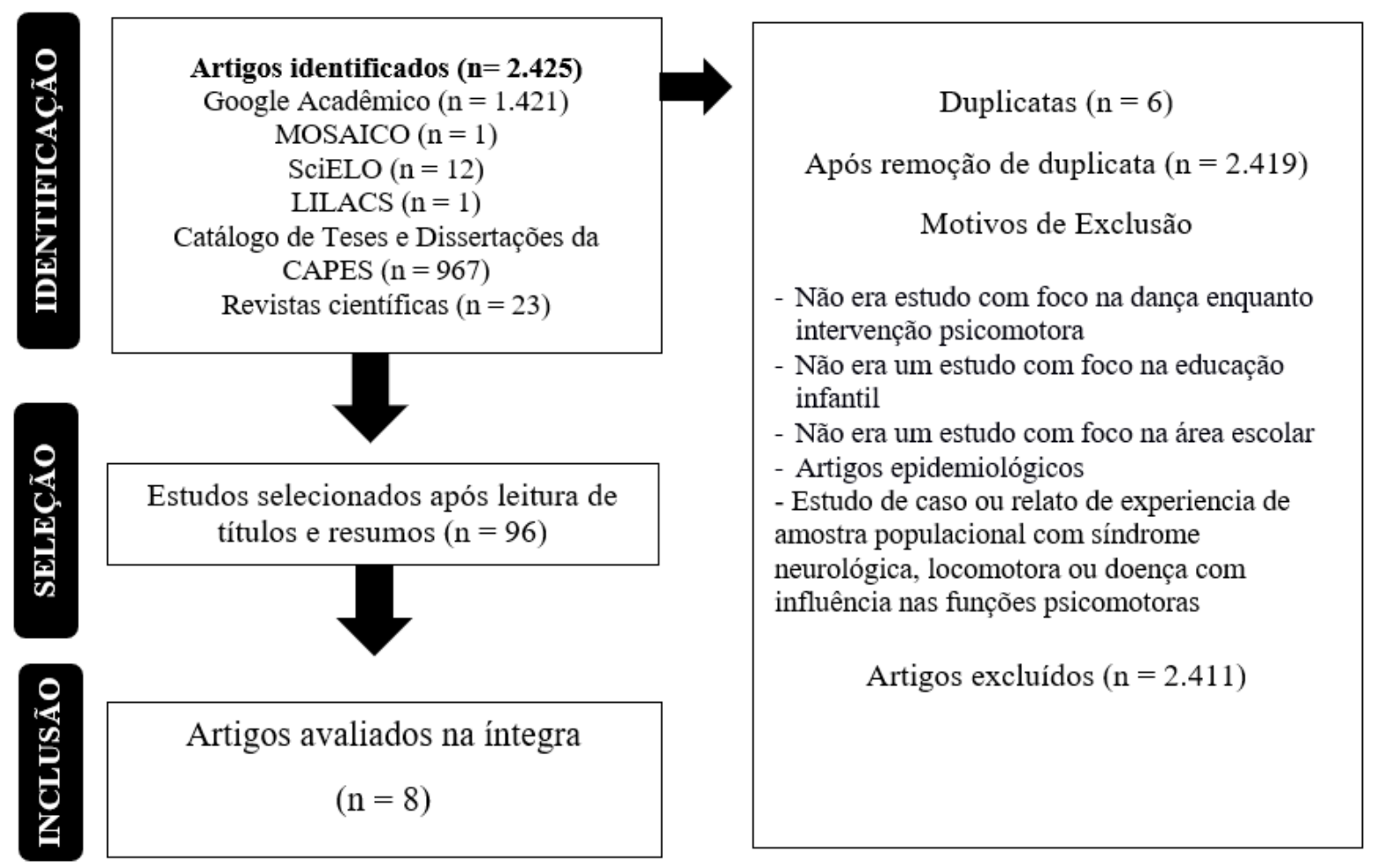

Fonte: elaborado pelos autores

\subsection{Apresentação dos artigos}

A presente sessão apresenta as principais características dos estudos encontrados de modo a dividir as categorias de análise em artigos publicados em anais e periódicos; TCCs e Dissertação de Mestrado. As produções foram distribuídas entre os anos 2012 e 2018, sendo este último o de maior expressividade apresentando aproximadamente 37,5\% dos estudos retidos para revisão. Em geral, as categorias foram distribuídas em 25\%, 62\% e 12\% respectivamente entre artigos, TCCs e uma dissertação de mestrado (ver Tabela 1). Os achados indicam que $75 \%$ das produções estão diretamente ligadas ao curso superior em educação física, o restante se distribui em dois cursos de pós-graduação, sendo um a nível de mestrado (Stricto Sensu) em educação física e outro a nível de especialização (Lato Sensu) em psicomotricidade. Todos os trabalhos foram desenvolvidos no âmbito da educação física e psicomotricidade.

Tabela 1. Principais características dos estudos incluídos na revisão

\begin{tabular}{llll}
\hline AUTOR & TÍTULO & CATEGORIA & ORIGEM \\
\hline $\begin{array}{l}\text { Oliveira \& Sousa } \\
(2012)\end{array}$ & Contribuições da dança no contexto escolar. & $\begin{array}{l}\text { TCC } \\
\text { Licenciatura em } \\
\text { Educação Física }\end{array}$ & $\begin{array}{l}\text { Centro Universitário UNIFACVEST, } \\
\text { Lages-Santa Catarina }\end{array}$ \\
\hline Lino (2013) & $\begin{array}{l}\text { Possibilidades didático-pedagógicas no trato } \\
\text { da dança na educação física infantil na escola }\end{array}$ & $\begin{array}{l}\text { TCC } \\
\text { (Licenciatura em } \\
\end{array}$ & $\begin{array}{l}\text { Educação Física) } \\
\text { Jacobina-BA. }\end{array}$ \\
\hline Lopes (2016) & $\begin{array}{l}\text { Dança na educação física escolar: educação } \\
\text { infantil. }\end{array}$ & $\begin{array}{l}\text { TCC } \\
\text { (Licenciatura em }\end{array}$ & $\begin{array}{l}\text { Centro Universitário de Brasília, } \\
\text { Brasília-DF }\end{array}$ \\
& & Educação Física) & \\
& & & \\
& & &
\end{tabular}


Research, Society and Development, v. 10, n. 12, e530101220718, 2021

(CC BY 4.0) | ISSN 2525-3409 | DOI: http://dx.doi.org/10.33448/rsd-v10i12.20718

\begin{tabular}{llll}
\hline $\begin{array}{l}\text { Kumagi \& } \\
\text { Inguaggiato } \\
(2016)\end{array}$ & $\begin{array}{l}\text { A inclusão da dança na educação infantil a } \\
\text { partir do olhar da psicomotricidade. }\end{array}$ & $\begin{array}{l}\text { TCC } \\
\text { (Especialização em } \\
\text { Psicomotricidade) }\end{array}$ & $\begin{array}{l}\text { Escola Bahiana de Medicina e Saúde } \\
\text { Pública, Salvador-Bahia. }\end{array}$ \\
\hline Silva (2018) & $\begin{array}{l}\text { Contribuições da dança nos aspectos } \\
\text { psicomotores em crianças de 6 a 8 anos de } \\
\text { idade nas aulas de educação física: uma } \\
\text { revisão da literatura. }\end{array}$ & $\begin{array}{l}\text { TCC } \\
\text { (Licenciatura em } \\
\text { Educação Física) }\end{array}$ & $\begin{array}{l}\text { Universidade Federal de Pernambuco, } \\
\text { Vitória de Santo Antão, Pernambuco }\end{array}$ \\
\hline Neves (2014) & $\begin{array}{l}\text { Dança e Psicomotricidade: Propostas do } \\
\text { ensino da dança na escola. }\end{array}$ & Artigo & $\begin{array}{l}\text { Revista SCIAS-Arte/Educação } \\
\text { ISSN 2318-8531 }\end{array}$ \\
\hline $\begin{array}{l}\text { Lima \& } \\
\text { Nascimento } \\
\text { (2018) }\end{array}$ & $\begin{array}{l}\text { A dança como recurso didático psicomotor } \\
\text { para o desenvolvimento da expressão criativa } \\
\text { e da descoberta do corpo no espaço da } \\
\text { educação infantil. }\end{array}$ & Artigo & $\begin{array}{l}\text { Anais do III Seminário Internacional } \\
\text { em Sociedade e Cultura na Pan- } \\
\text { Amazônia }\end{array}$ \\
\hline Silva (2018) & $\begin{array}{l}\text { O brincar dançante: a criança e sua inerente } \\
\text { necessidade de brincar e se-movimentar pela } \\
\text { dança. }\end{array}$ & $\begin{array}{l}\text { Dissertação } \\
\text { (Mestrado em }\end{array}$ & $\begin{array}{l}\text { Universidade Federal de Santa Maria, } \\
\text { Rio Grande do Sul. }\end{array}$ \\
\hline
\end{tabular}

Fonte: dados da pesquisa

\subsection{Detalhamento e discussão dos estudos incluídos na revisão}

\subsubsection{Análise dos trabalhos de conclusão de curso de graduação e pós-graduação}

A presente sessão pretende apresentar os estudos que foram incluídos na revisão, de modo a detalhar e discutir os resultados a saber as principais considerações para aplicação da dança enquanto estratégia psicomotora nas aulas de educação física escolar.

No estudo de título “A inclusão da dança na educação infantil a partir do olhar da psicomotricidade” (Kumagi \& Inguaggiato, 2016), os autores tentam validar a prática da dança utilizando a psicomotricidade como facilitadora para o desenvolvimento da organização do esquema corporal e empoderamento da própria imagem corporal da criança. Traduz a ideia de que a dança é a arte do movimento e da expressão, onde a musicalidade e a estética prevalecem, e sua prática permite o desenvolvimento de qualidades nos indivíduos no seu físico, na sua psique e na sua mente.

O estudo traz um alerta para a preocupação que se deve ter ao trabalhar com atividades corporais para crianças. O conhecimento das fases de desenvolvimento psicomotor e a adequação dos estímulos em detrimento dessas fases. Por fim, a estrutura das aulas no que se refere a progressão pedagógica, tem implicação direto no engajamento da tarefa, fazendo com que as crianças se sintam capazes de realizá-las, contribuindo assim para sua autoestima e autonomia.

Os autores concluíram que a dança é uma arte bastante importante a ser trabalhada na educação infantil, e, que a técnica de dança não deve ser utilizada como foco central para o desenvolvimento psicomotor, levando em consideração o caráter criativo e expressivo inerentes da própria infância.

O estudo de título "Contribuições da dança nos aspectos psicomotores em crianças de 6 a 8 anos de idade nas aulas de educação física: uma revisão de literatura" (Silva, 2018), teve como principal objetivo identificar as habilidades psicomotoras básicas proporcionadas pela dança na escola durante as aulas de educação física.

O autor destaca que a dança não é uma temática bem explorada nas aulas de educação física devido à baixa relação dos professores com o conteúdo. Assim como no estudo anterior, a dança contribui para o desenvolvimento de crianças, de modo a se associar aos aspectos cognitivo, motor e social, assim como, promove a oportunidade da criança de se expressar e conhecer o mundo ao seu redor.

É nos anos iniciais do período escolar, que as crianças vivenciam a maior parte dos movimentos, afetos e cognições de forma lúdica. Por fim, o texto conclui que a dança quando se alia a psicomotricidade possibilita um aprimoramento no 
desenvolvimento humano da criança, ocasionando em um melhor domínio da coordenação motora geral, equilíbrio, noção de tempo e espaço, além da melhora na consciência corporal.

Oliveira \& Souza (2012) em “As contribuições da dança no contexto escolar”, refletiram sobre a importância da dança como instrumento de socialização, contribuindo com a formação de cidadãos críticos, participativos e responsáveis. Trata-se de uma pesquisa-ação que teve como amostra 10 professores da rede pública do município de Lages, no estado de Santa Catarina.

Para os autores a dança nas aulas de Educação Física, sendo uma experiência corporal, possibilitará aos alunos novas formas de expressão e comunicação, levando-os à descoberta da sua linguagem corporal, que contribuirá para o processo ensino aprendizagem nas demais disciplinas curriculares.

Além disso, os dados coletados sugerem que a disciplina de Educação Física pode contribuir com o desenvolvimento da socialização, da linguagem corporal, da cultura, da coordenação motora, da lateralidade e de habilidades motoras de alunos da educação infantil. Segundo os professores, esses aspectos são trabalhados a partir de atividades lúdicas, recreação, jogos, psicomotricidade, dança, ginástica e esporte.

Desta forma, os autores entendem que a dança é uma ferramenta importante para o desenvolvimento biopsicossocial dos alunos da educação infantil, que possibilita uma melhora significativa em seu comportamento social, além de desenvolver os aspectos cognitivos e motor, resultando na formação de um cidadão ético, formador de suas opiniões e ideias.

Lino, (2013) desenvolveu o trabalho "Possibilidades didático-pedagógicas no trato da dança na educação infantil na escola", elucidando a dança como conteúda da educação física com as abordagens pedagógicas da disciplina, são elas psicomotricidade, desenvolvimentista, construtivista, crítico-superadora, crítico-emancipatória e cultural. O estudo foi subdivido em quatro capítulos, de modo que em seu quarto capítulo a dança foi relacionada a cada uma das abordagens supracitadas.

Embora a pesquisa conclua que não há uma proposta pedagógica superior ou inferior a outra para utilizar a dança na educação infantil, a autora atenta para o fato dela (a dança) estar intimamente atrelada com a abordagem psicomotricista, enfatizando que a sintonia entre elas está no agir partindo do controle e consciência de movimentos associados às ações cognitivas de forma expressiva. Em outras palavras, independentemente de suas peculiaridades, quando usada de forma adequada, a dança se torna uma aliada na formação para o desenvolvimento holístico das crianças.

“Dança na educação física: educação infantil" proposta de revisão desenvolvida por Lopes (2016) por meio de artigos científicos previamente publicados. Segunda a autora, a dança enquanto proposta de intervenção nas aulas de educação fisica é capaz de auxiliar para um melhor desenvolvimento físico, cognitivo e afetivo das crianças. O ensino da dança nas aulas de educação física está para além das danças coreografadas como forma de arte. Ou seja, quando atrelada a psicomotricidade, possibilita ampliar suas habilidades contribuindo para a descoberta de novos movimentos, permitindo que aflore sua criatividade e vivencie a linguagem corporal, melhorando sua comunicação com o outro e com o meio. Além disso, com base nos estudos revisados, a autora conclui que a dança na educação infantil promove experiências com o corpo capazes de aflorar a criatividade, o ritmo, a consciência corporal, a socialização e o senso ético, destacando-os enquanto elementos de grande relevância para o processo de formação global da criança.

\subsubsection{Análise das dissertações de mestrado}

"O brincar dançante: a criança e sua inerente necessidade de brincar e se-movimentar pela dança” (Silva, 2018), buscou investigar se através do "brincar dançante" seria possível reintroduzir a criança, oprimida em seu cotidiano por diversos fatores, ao mundo do brincar e se movimentar. Trata-se de uma investigação teórica que dialoga com autores sobre o tema. 
Research, Society and Development, v. 10, n. 12, e530101220718, 2021

(CC BY 4.0) | ISSN 2525-3409 | DOI: http://dx.doi.org/10.33448/rsd-v10i12.20718

A autora nos lembra da importância da dança como uma possibilidade de intervenção da Educação Física, como conteúdo de experimentação de movimentos. Através da dança é possível incentivar desde cedo a comunicação e a expressão das crianças, é um meio pelo qual ela desenvolve a linguagem corporal e aprende a conhecer seu corpo e suas capacidades.

A autora ressalta outros aspectos que podem ser estimulados através da dança como, por exemplo, a imaginação, a criatividade, o senso de cooperação, a solidariedade, o respeito, o autoconhecimento, a descoberta de si próprio, de suas particularidades e especificidades, o que leva o aluno a aproveitar mais suas experiências por fazê-las de maneira consciente e crítica.

\subsubsection{Análise dos artigos publicados em anais e periódicos}

O trabalho de título "Dança e psicomotricidade: propostas do ensino da dança na escola" (Neves, 2014) investigou exercícios de dança baseados em atividades psicomotoras com o intuito de contribuir para o desenvolvimento de crianças de 05 a 07 anos de idade. A autora enxerga a dança como uma forma de exprimir sentimentos através do movimento humano e através de um estudo bibliográfico traz a informação de que a dança aplicada no ambiente escolar contribui para o aluno, ativando capacidades positivas, adquirindo confiança e maturidade, desenvolvendo habilidades motoras e favorecendo a socialização, aprendendo também a importância do cuidado com o corpo e saúde.

O estudo apresenta uma questão onde a preocupação do ensino não deve ser voltada para a quantidade de atividades, e sim na qualidade, focando na participação dos alunos, estimulando-os a criarem e recriarem sua própria movimentação.

Por fim, a autora chega à conclusão de que o ensino da dança não se resume apenas como arte, onde se criam coreografias, mas que a sua ação pedagógica pode contribuir em diversos aspectos no desenvolvimento da criança, objetivando benefícios estéticos e artísticos e propiciando uma forma de comunicação, conhecimento e expressão. A sua prática nas escolas segundo conclusão da autora, poderá auxiliar na formação de uma criança mais criativa, afetiva, critica e reflexiva com uma maior interação social.

Corroborando as ideias de Neves (2014), Lima \& Nascimento (2018), no artigo intitulado "A dança como recurso didático psicomotor para o desenvolvimento da expressão criativa e da descoberta do corpo no espaço da educação infantil" acrescentam que a educação infantil é um dos principais fatores extrínsecos paro o processo de desenvolvimento holístico dos educandos. Além disso, os autores indicam que as atividades diversificadas, assim como a dança na educação infantil, promovem a socialização e o desenvolvimento da identidade da criança enfatizando que essas atividades devem estar presentes na educação infantil de forma lúdica. Os autores chamam a atenção para a forma com a qual a dança deve ser introduzida nesse espaço visando todo o desenvolvimento das capacidades já mencionadas. O passo a passo da progressão pedagógica, assim como as possibilidades de troca entre diferentes aulas do conhecimento são fatores importantes. Além disso, as danças devem fazer parte do planejamento das aulas para além das datas festivas.

\subsubsection{Considerações para aplicação da dança enquanto proposta psicomotora}

O presente estudo teve como objetivo analisar quais são as estratégias utilizadas e quais são os possíveis retornos da dança na Educação Infantil nas aulas de Educação Física Escolar. Após o detalhamento dos estudos retidos para revisão podemos observar que a dança enquanto estratégia psicomotora nas aulas de educação física é uma ferramenta pedagógica de grande expressividade, assim como outras estratégias de jogos e brincadeiras discutidos em trabalhos de revisões previamente publicados sobre a educação infantil (Santos, 2019).

Outro fator observado na sumarização dos textos é a preocupação quanto a formação dos professores que irão atuar com essa temática da dança no âmbito da educação infantil. Este fato corrobora diferentes pesquisas que buscaram entender os 
processos formativos, o cotidiano e tensões que permeiam essa prática ao longo dos anos (Brasileiro, 2002; Neira, 2017; Palma, et al., 2018).

A dança enquanto estratégia psicomotora já foi estudada em outras áreas, como é o caso da disciplina de artes, que assim como a educação física, possui papel significativo na expressividade da comunicação e na formação de um ser global (Viana, 2018).

Os achados da presente revisão apontam que a temática dança nas aulas de educação física na educação infantil deve ser desenvolvida de forma natural, sem a obrigatoriedade de criação e imitação de coreografias. Além disso, os estudos parecem concordar quanto as sugestões e possibilidades para se trabalhar a dança no ambiente educacional, como por exemplo, através de jogos-canções, atividades musicais, contos e cantigas de roda populares do Brasil. O ritmo dessas cantigas é cadencial, agradável e traz possibilidades de movimento e aprendizagem para as crianças que contribui para o seu desenvolvimento integral.

Outro dado detectado em nosso estudo, alerta para o fato que embora as diferentes categorias (artigos, TCCs e dissertações) sejam consensuais quanto a sua eficácia, observamos certa carência de estudos a nível de pós-graduação nos diferentes níveis (especialização, mestrado e doutorado). Além disso, o retorno das buscas em periódicos científicos da área foi baixo, o que pode ter contribuído para inclusão de poucos artigos. Tal fato, pode estar relacionado a falto de importância e negligência da temática em questão nos espaços escolares, assim como, a falta de preparação do corpo docente. Outro fato muito evidenciado nas propostas analisadas.

\section{Considerações Finais}

Após revisar a literatura e detalhar os resultados de modo a auxiliar professores(as) e pesquisadores(as) a compreenderem as contribuições, os conceitos, os desafios e as perspectivas dessa temática aplicada a educação infantil, no que pese a estrutura das aulas, destacamos algumas considerações que julgamos essenciais para as intervenções no campo escolar. A quantidade de atividades não é o essencial, a qualidade faz a diferença. Para que uma proposta de dança enquanto intervenção psicomotora tenha sucesso, sugerimos que a liberdade de expressão, as fases de desenvolvimento psicomotor, e a progressão pedagógica das aulas respeitem as subjetividades de cada educando, assim como, o contexto sociocultural em que se encontra inserido. Uma proposta interessante seria utilizar a própria cultura corporal de movimento do contexto social em que as crianças se encontram inseridas. A guisa de ilustração, as brincadeiras e jogos cantados, as danças folclóricas e regionais.

No que se refere a progressão pedagógica, as tarefas devem ser organizadas de acordo com o grau de dificuldade, de modo que os estímulos sejam graduais e permitam tempo de adaptação e subsequentemente acomodação das funções psicomotoras e capacidades cognitivas relacionadas. O tempo médio para que esse processo apresente significativa resposta é tão individual, subjetivo e particular, quanto as dimensões já citadas. Nesse sentido, entendemos que as respostas e melhorias nas funções psicomotoras acontecerão mediante a realidade que compreende a subjetividade de cada ser.

No contexto da educação física escolar, as danças ampliam os repertórios de movimento, possibilitando assim, diferentes experiências que se transbordam para além das datas comemorativas e folclóricas. Sua aplicação possibilita melhoria na expressão de sentimentos e na estruturação das funções psicomotoras que as crianças necessitam para sua formação global. Naturalmente, as propostas serão traduzidas para o cotidiano dessas crianças, contribuindo para sua autonomia e tomada de decisão, ampliando assim, sua comunicação eficaz com o mundo.

Por fim, a temática dança enquanto intervenção psicomotora no âmbito da educação infantil, permanece um campo amplo e promissor para futuras discussões e produções científicas. A carência de intervenções sugeri que a dança na escola ainda é uma temática pouco explorada ou negligenciada. Tal fato pode ser fator ponderador que reverbera no baixo quantitativo de 
Research, Society and Development, v. 10, n. 12, e530101220718, 2021

(CC BY 4.0) | ISSN 2525-3409 | DOI: http://dx.doi.org/10.33448/rsd-v10i12.20718

estudos retidos para análise. Nesse sentido, baseando-se nos achados aqui apresentados, levando em consideração as características dessa temática na escola e visando contribuir para uma educação física escolar significativa, sugere-se que novos estudos sejam realizados de modo a detalhar o cotidiano da escola e as estratégias pedagógicas, assim como, as possíveis adaptações nos diferentes espaços e contextos em que a comunidade escolar esteja inserida.

\section{Referências}

Aquino, M. F. S., Browne, R. A. V., Sales, M. M., \& Dantas, R. A. E. (2012). A psicomotricidade como ferramenta da educação física na educação infantil. RBFF-Revista Brasileira de Futsal e Futebol, 4(14).

Barreto, P. M., Modesto, V. O., \& Rezende, K. C. (2021). O (DES) AVANÇO NEOLIBERAL DA BNCC E A EDUCAÇÃO FÍSICA: Uma educação para o mercado de trabalho. Revista Fluminense de Educação Física, 1(1).

Gomes, G. V., \& da Silva Souza, M. (2021). Formação de professores em Educação Física pós-BNCC. Germinal: Marxismo e Educação em Debate, 13(2), $858-873$.

Boente, A., \& Braga, G. (2004). Metodologia científica contemporânea para universitários e pesquisadores. Rio de Janeiro: Brasport, 79-98.

Brasil. (1997). Secretaria de Educação Fundamental. Parâmetros curriculares nacionais: Educação física / Secretaria de Educação Fundamental. - Brasília: MEC/SEF.

Brasil. (2001). Parâmetros Curriculares Nacionais para o Ensino Fundamental: educação física. Brasília, MEC/SEF.

Brasileiro, L. T. (2002). O conhecimento no currículo escolar: o conteúdo dança em aulas de Educação Física na perspectiva crítica. Movimento (ESEFID/UFRGS), 8(3), 5-18.

Carmo, A. P. M., \& Cintra, K. I. (2016) A dança como elemento de mediação no desenvolvimento da psicomotricidade. Trabalho de Conclusão de Curso (TCC). Licenciatura em Educação Física - Faculdade Calafiori, Minas Gerais.

Darido, S. C., \& Rangel, I. C. A. (2000). Educação Física Na Escola: Implicações Para a Prática Pedagógica. Grupo Gen-Guanabara Koogan.

Diniz, T. N., \& Santos, G. D. L. (2009). História da dança-Sempre. Seminário de Pesquisa em Ciências Humanas. Org. DONAT, M.

Dobbins, M., Cockerill, R., Barnsley, J., \& Ciliska, D. (2001). Factors of the innovation, organization, environment, and individual that predict the influence five systematic reviews had on public health decisions. International journal of technology assessment in health care, 17(4), 467-478.

Falsarella, A. P., \& Amorim, D. B. (2008). A importância da dança no desenvolvimento psicomotor de crianças e adolescentes. Conexões, 6, $306-317$.

Féres, N. (2016). O despertar do ritmo e da consciência corporal na infância através das aulas de dança. Trabalho de Conclusão de Curso (TCC). Universidade Estadual Paulista, Rio Claro.

Fonseca, V. D. (2008). Desenvolvimento psicomotor e aprendizagem. Porto Alegre: Artmed, 15-73.

Franco, N., \& Ferreira, N. V. C. (2016). Evolução da dança no contexto histórico: aproximações iniciais com o tema. Repertório, Salvador, $26,266-72$.

Galvão, T. F., Pansani, T. D. S. A., \& Harrad, D. (2015). Principais itens para relatar Revisões sistemáticas e Meta-análises: A recomendação PRISMA. Epidemiologia e Serviços de Saúde, 24, 335-342.

Gariba, C. M. S., \& Franzoni, A. (2007). Dança escolar: uma possibilidade na Educação Física. Movimento (ESEFID/UFRGS), 13(2), 155-171.

Gomes, A. S. M., \& Nista-Piccolo, V. L. (2007). Uma análise fenomenológica do dançar nos discursos dos formandos em Educação Física (Doctoral dissertation, Dissertação de mestrado). São Paulo (SP): Universidade São Judas Tadeu).

Gomes, W. (2017). A dança como fator de desenvolvimento psicomotor na educação infantil. Revista de Iniciação Científica da Universidade Vale do Rio Verde, 6(2).

Kitchenham, B., Mendes, E., \& Travassos, G. H. (2006). A systematic review of cross-vs. within-company cost estimation studies. In 10th International Conference on Evaluation and Assessment in Software Engineering (EASE) 10 (pp. 1-10).

Kumagi, L. C. D. S., \& Inguaggiato, M. L. (2016). A inclusão da dança na educação infantil a partir do olhar da psicomotricidade. Trabalho de Conclusão de Curso (TCC). Escola Bahiana de Medicina e Saúde Pública, Salvador.

Lima, C. A. B., \& Do Nascimento, M. D. J. L. (2018). A Dança como Recurso Didático Psicomotor para o Desenvolvimento da Expressão Criativa e da Descoberta do Corpo no Espaço da Educação Infantil. Anais do III Seminário Internacional em Sociedade e Cultura na Pan-Amazônia, 1-13.

Lino, E. D. (2013). Possibilidades didático-pedagógicas no trato da dança na educação física infantil na escola. Trabalho de conclusão de curso (Licenciatura plena em Educação Física). Universidade do Estado da Bahia, Jacobina-BA. 
Research, Society and Development, v. 10, n. 12, e530101220718, 2021 (CC BY 4.0) | ISSN 2525-3409 | DOI: http://dx.doi.org/10.33448/rsd-v10i12.20718

Lopes, B. M. D. S. (2016). Dança na educação física escolar: educação infantil. Trabalho de conclusão de curso (Licenciatura em Educação Física). Centro Universitário de Brasília, Brasília-DF.

Maciel, C. L. A., Santo, L. P. E., Fernandes, C. T., Maciel, C. M. L. A., \& Reis Filho, A. D. (2016). As contribuições da dança no desempenho motor de crianças da educação infantil. Arquivos em Movimento, 11(2), 29-46.

Magalhães, M. J. (2021). Bumba meu boi: uma reflexão das danças do brasil. Ócio, Jogo e Brincadeira: Aprendizagens e Mediação Intercultural, 77.

Marques, A. P. C. R., \& Selow, M. L. C. (2017). A contribuição da dança para o desenvolvimento da criança na educação infantil. Vitrine de Produção Acadêmica Produção de Alunos do Centro Universitário Dom Bosco, 4(1).

Marques, I. A. (1998). Corpo, dança e educação contemporânea. Pro-posições, 9(2), 70-78.

Nascimento, D. E., \& da Silva Lopes, S. (2021). ARTE NA ESCOLA: AMPLIANDO CONHECIMENTOS E CONCEPÇÕES SOBRE/EM/PARA A DANÇA. Humanidades \& Inovação, 8(33), 251-262.

Neves, A. D. M. (2014). Dança e Psicomotricidade: Propostas do ensino da dança na escola. SCIAS-Arte/Educação, (3), 67-85.

Neira, M. G. (2017). O currículo de educação física e o posicionamento dos sujeitos. Revista Contemporânea de Educação, 11(22), $367-384$.

Oliveira, S. A., \& Sousa, F. J. F. (2012). As contribuições da dança no contexto escolar. Trabalho de Conclusão de Curso (TCC). Centro Universitário UNIFACVEST, Lages-SC.

Palma, Â. P. T. V., Oliveira, A. A. B., \& Palma, J. A. V. (2018). Educação Física e a organização curricular: educação infantil, ensino fundamental e ensino médio. SciELO-EDUEL.

Santos, L. S. M. R. D. (2019). Análise da importância da psicomotricidade na educação infantil. Trabalho de Conclusão de Curso (TCC). Centro Universitário de Brasíli, Brasília.

Santos, L.S. (2019). Análise da importância da psicomotricidade na educação infantil. Trabalho de Conclusão de Curso (TCC). Centro Universitário de Brasíli, Brasília.

Silva Holanda, G. I., Lasch, J. V., \& Dias, R. F. (2021). A Educação Física na BNCC: desafios da escola republicana. Motrivivência, 33(64), 1-18.

Silva Mello, A., Zandominegue, B. A. C., Barbosa, R. F. M., Martins, R. L. D. R., \& Santos, W. (2016). A educação infantil na Base Nacional Comum Curricular: pressupostos e interfaces com a Educação Física. Motrivivência, 28(48), 130-149.

Silva, D. A. (2008). A importância da psicomotricidade na educação infantil. Trabalho de Conclusão de Curso (TCC). Centro Universitário de Brasília UniCEUB Faculdade de Ciências da Educação e Saúde - FACES, Brasília.

Silva, L. P. B. D. (2018). Contribuições da dança nos aspectos psicomotores em crianças de 6 a 8 anos de idade nas aulas de educação física: uma revisão da literatura. Trabalho de Conclusão de Curso (TCC). Universidade Federal de Pernambuco, Vitória de Santo Antão.

Silva, T. M. R. D. (2018). O brincar dançante: a criança e sua inerente necessidade de brincar e se-movimentar pela dança. Dissertação (Mestrado em Educação Física). Universidade Federal de Santa Maria, Santa Maria-RS.

Sousa, D. C. D. (2004). Psicomotricidade: integração pais, criança e escola. Fortaleza: Ed. Livro Técnico.

Souza, G. M. D. D. (2018). A estruturação espaço-temporal a partir da dança na Educação Física Escolar: contribuições para a educação psicomotora. Trabalho de Conclusão de Curso (TCC). Universidade Federal Rural de Pernambuco, Recife.

Thomas, J. R., \& Nelson, J. K. (2012). Silverman. Métodos de Pesquisa em Atividade Física. Tradução: Ricardo Demétrio de Souza Petersen. $6^{a}$ ed., Porto Alegre: Artmed, 478p.

Verderi, E.B.L.P. (2000). Dança na escola. 2. ed. Rio de Janeiro: Sprint. 